\title{
A ZERO-ONE MODEL FOR PROJECT PORTFOLIO SELECTION AND SCHEDULING
}

\author{
by
}

\author{
Fereidoun Ghasemzadeh, Norm Archer \\ and Paul Iyogun
}

\author{
Innovation Research Working Group \\ WORKING PAPER NO. 59
}

December 1996

The Working Paper series is intended as a means whereby a researcher may communicate his or her thoughts and findings to interested readers for their comments. The paper should be considered preliminary in nature and may require substantial revision. Accordingly, this Working Paper should not be quoted nor the data referred to without the written consent of the author. Your comments and suggestions are welcome and should be directed to the author. 


\title{
A Zero-One Model for Project Portfolio Selection and Scheduling
}

\author{
by \\ Fereidoun Ghasemzadeh and Norm Archer \\ Michael G. DeGroote School of Business, MeMaster University, Hamilton, Ont., Canada, L8S 4M4
}

\section{Paul Iyogun}

School of Business and Economics, Wilfrid Laurier University, Waterloo, Ont., Canada, N2L 3C5

This work was funded by a research grant from the Innovation Research Centre, Michael G. DeGroote School of Business, McMaster University. 


\begin{abstract}
A zero-one integer linear programming model is proposed for selecting and scheduling an optimal project portfolio, based on the organization's objectives, and constraints such as resource limitations and interdependence among projects. The major contribution of the paper is that the proposed model not only suggests projects that should be incorporated in the optimal portfolio, but it also determines the starting period for each project. Scheduling considerations can have a major impact on the combination of projects that can be incorporated in the portfolio, and may allow the addition of certain projects to the portfolio that could not have been selected otherwise. Moreover, the model handles situations that frequently happen in real world applications, in which the amount of available and consumed resources varies in different periods. An example problem is described and solved with the proposed model to illustrate the approach, and some areas for future research are discussed.
\end{abstract}


Table of Contents

Topic

Page

1. Introduction ....................................................................................................................... 4

2. A zero-one ILP model for project portfolio selection and scheduling.......... 6

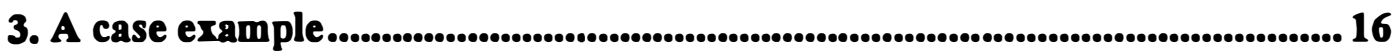

4. Summary and discussion ........................................................................... 20

References ........................................................................................................ 22

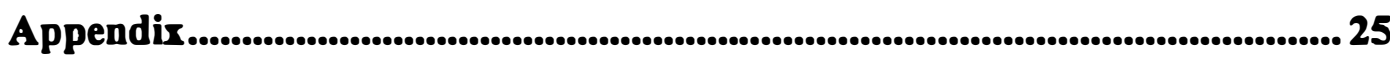




\section{Introduction}

Selecting projects to develop from the many projects that are usually possible, or "project portfolio selection" is a crucial decision in many organizations, where serious effort are made to estimate, evaluate, and choose optimal sets of projects (Dos Santos, 1989). Some of the criteria that have to be addressed in the process of project portfolio selection are the organization's objectives and priorities, financial benefits, intangible benefits, availability of resources, and risk level of the project portfolio (Schniederjans and Santhanam, 1993). Difficulties associated with project portfolio selection result from several factors, as noted below.

1. There are multiple and often conflicting objectives (or criteria) associated with the selection of projects to include in a project portfolio. Even when all objectives have been identified, one still has the problem associated with determining the trade-offs among the various criteria. For example, are economic objectives more important than political objectives, and if so, how much more important?

2. Some of the objectives are qualitative, as opposed to quantitative, in nature. For example, enhancing the image of the organization or promoting national pride through performing ambitious projects are qualitative objectives. Integrating qualitative and quantitative objectives for such projects is difficult.

3. There is a large amount of uncertainty associated with the scoring of individual projects on a specific criterion. For example, the net present value (NPV) of a new product that is under development can be highly uncertain. Moreover, there are certain risks, such as technical and market risk, that should be addressed during project portfolio selection.

4. Some projects in particular portfolios may be highly interdependent in nature. For example, an Executive Information System (EIS) may require the completion of one or more precursor projects, such as upgrades or installation of certain transaction processing applications (TPS), each of which could have benefits in its own right. Mutually exclusive 
projects (a set of projects among which only one can be selected), is another example of interdependence among projects that should be addressed.

5. In addition to the difficulties associated with portfolio objectives, due to resource limitations there are usually constraints such as finance, work force, and machines, to be considered in the decision making process. As some researchers have noted, a major reason why some projects are selected but not completed is that resource limitations are not always formally included in the project portfolio selection process. Therefore, in cases where resource limitations are at fault for a failed project, a selection model that incorporates resource limitations may aid the decision maker in avoiding such mistakes (Schniederjans and Santhanam, 1993). Project portfolio selection becomes more difficult when resource availability and consumption are not uniform over time.

6. The selected portfolio may need to be balanced in terms of factors, such as risk and time to completion, that are of importance to decision makers. For example, although high-risk projects often have greater expected benefits one should be careful about putting too many resources into high-risk projects.

7. The number of feasible portfolios is often enormous. For example, if there were 20 candidate projects for a time frame of five periods, the number of combinations (project portfolios) that could be considered is $2^{100}$, assuming a go/no go decision for each project in each period.

In an attempt to overcome these difficulties, in this paper we will propose an optimization model for selecting and scheduling an optimal project portfolio. Following this, an example problem is described and solved to illustrate the approach, and finally some areas for future research are discussed. 


\section{A zero-one ILP model for project portfolio selection and scheduling}

In order to select and schedule a project portfolio we have adopted an optimization approach. The approach in this paper considers the entire feasible solution space and finds a portfolio that maximizes the overall objectives of the organization while satisfying constraints, such as resource limitations and interdependence among projects. The zero-one linear programming model is appropriate since projects are either selected or not selected.

As project portfolio selection is usually a multi-objective problem involving optimization of benefits in several categories under certain constraints, one approach to solving this problem is using zero-one Multiple Criteria Decision Making (0-1 MCDM) techniques (For a comprehensive review of 0-1 MCDM techniques see Rasmussen, 1986). However, due to the problems and difficulties associated with pure multiple criteria problems (Evans, 1984 and Rasmussen, 1986) we adopted the zero-one integer programming approach for formulating and solving the problem. In the proposed approach, when there is more than one objective involved in decision making, the multiple objectives are first integrated by means of a weighted value function, and reduced to one objective that will be maximized by the model. Also, in order to avoid the difficulties associated with non-linear problems, we have assumed the use of a linear additive value function (Evans and Fairbaim, 1989). This permits the use of a zero-one Integer Linear Programming (0-1 IIP) model.

The proposed approach enables decision makers to a) consider multiple, conflicting goals, b) consider qualitative objectives, c) explicitly consider constraints such as resource limitations, project interdependencies, and portfolio balancing, and d) select and schedule the optimal set of projects that will maximize benefits according to the prespecified priorities without violating any of the constraints. 
Few zero-one IIP models have been suggested in the literature for project portfolio selection. The models proposed by Evans and Fairbaim (1989) and Kira et al. (1990) address many of the real issues more so than other models in the project portfolio selection literature. However, in spite of their advantages, these models have some shortcomings in that they either do not take the starting period of projects into consideration (Evans and Fairbaim, 1989) and implicitly assume that all of the projects start in the first period of the planning horizon, or assume that the amount of resource that is consumed in each period is fixed over time (Kira et al., 1990).

A serious error that could be made by the model, because of the assumption that projects start in the first period of the planning horizon, is an incorrect estimate of the total amount of resource to be used in each period. This can cause the unnecessary elimination of some projects from the portfolio because of perceived shortages of resources in specific periods, whereas this shortage would not happen in reality because some of the projects could start in later periods.

The assumption of a fixed rate for resource consumption during the execution period, is not a valid assumption either. In real world cases, usually the rate of resource consumption is low in the earlier periods and increases as time passes, then around the middle of execution it reaches a peak; after that, the consumption rate decreases and finally converges to zero at the end of the project. Therefore, the curve that represents cumulative resource consumption over time is usually an S-curve curve (for example, see Nicholas, 1990). The slope of the S-curve depends on the type of project at hand; some projects have steeper while others have more gentle slopes. Figures 1 and 2 show typical resource and cumulative resource consumption curves over time.

The proposed model in this paper overcomes the above mentioned shortcomings. It not only suggests a set of projects that should be incorporated in the optimized portfolio, but also determines the period in which each of the selected projects should start. The model also handles the situations in which the amount of consumed resources 
Figure 1- Resource Consumption Over Time

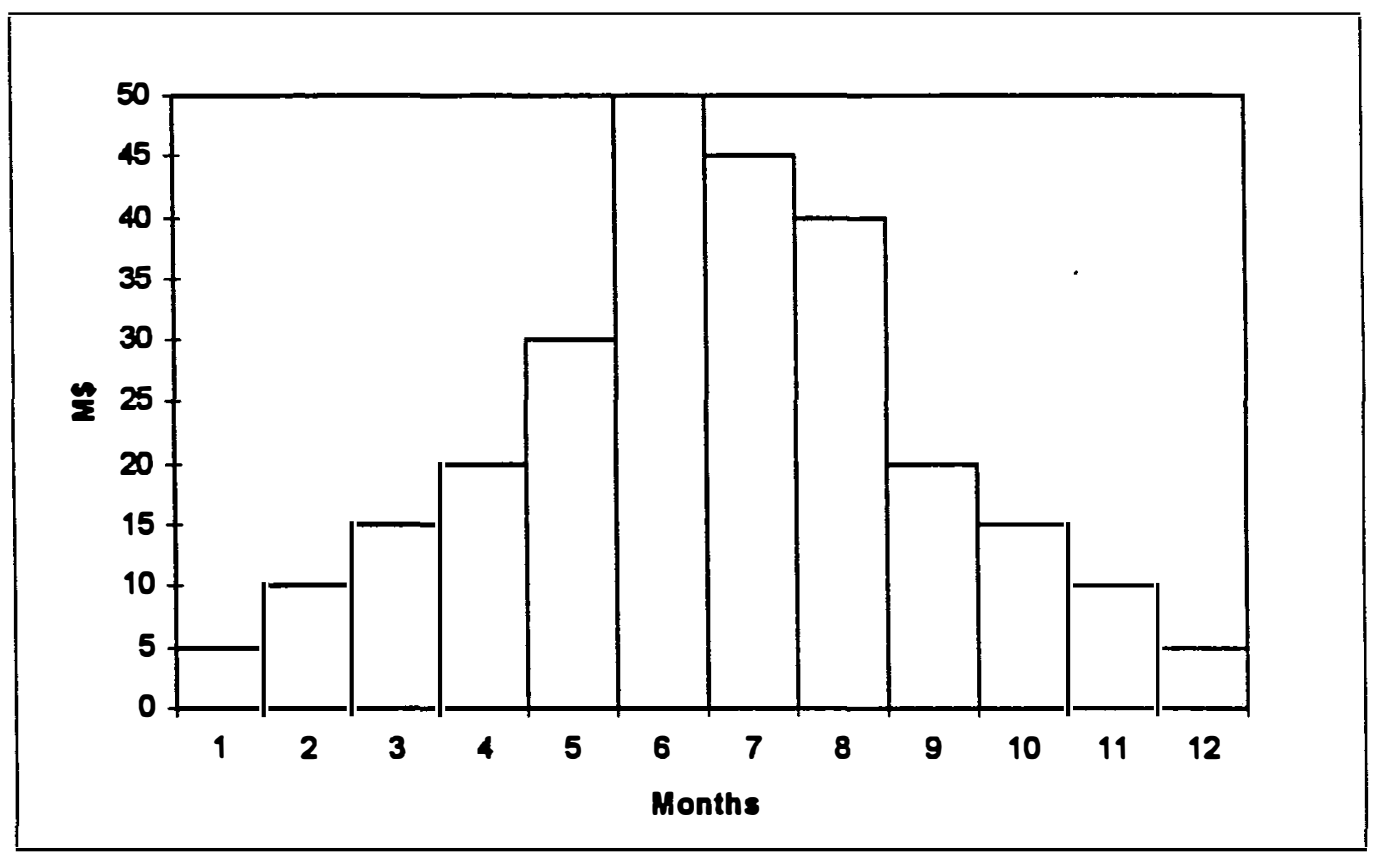

Figure 2- Cumulative Resource Consumption Over Time

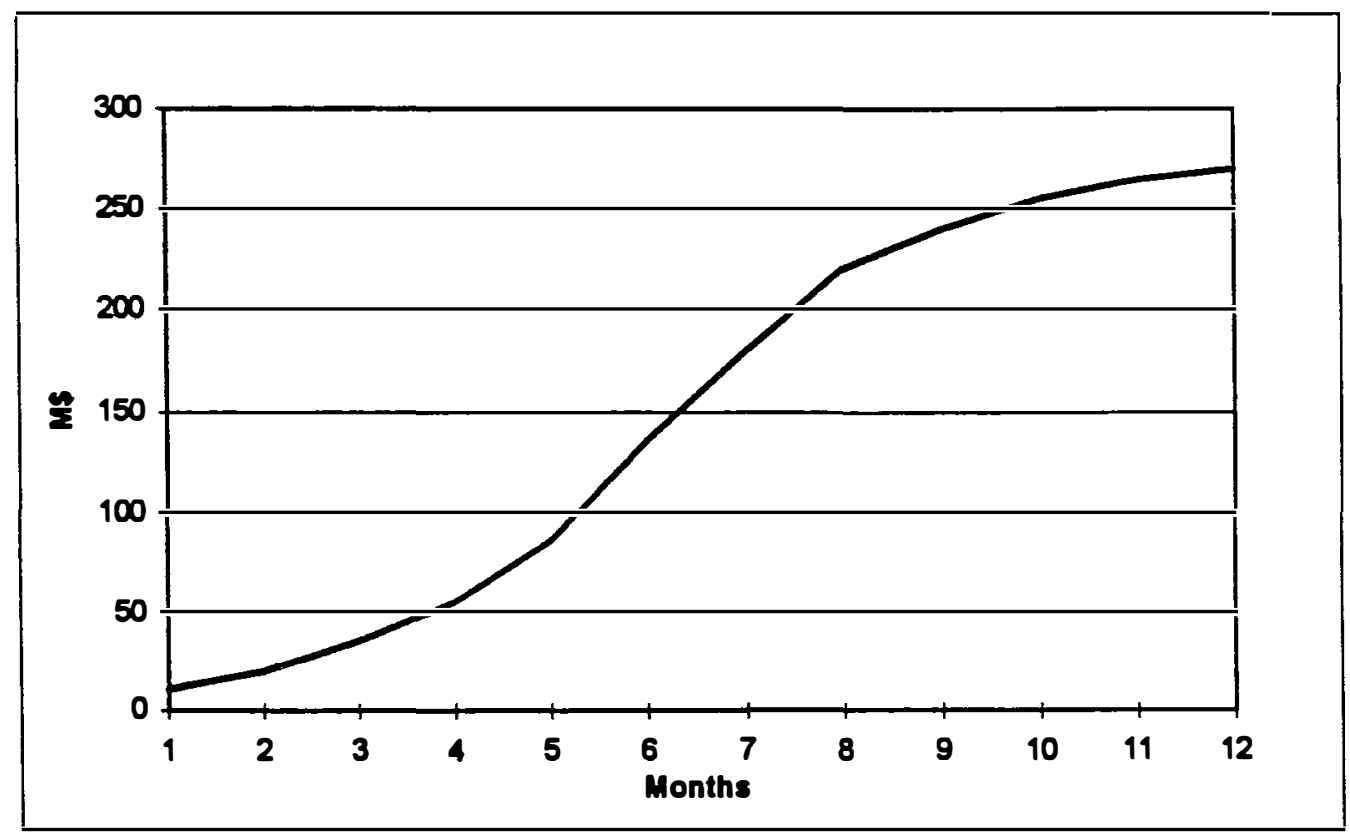


varies in different periods. The other advantage of the proposed model is that it is not limited to certain pre-defined scheduling or resource consumption alternatives (as is the case with previously mentioned models), and searches the entire solution area in order to find the global optimal solution.

\subsection{The model}

The decision variables, objective function, and constraints of the models are as follows:

\section{Decision Variable}

The decision variables are defined by $X_{i j}= \begin{cases}1 & \text { if project } \mathrm{i} \text { is included in the portfolio and starts in period } \mathrm{j} \\ 0 & \text { otherwise }\end{cases}$ for $\mathrm{i}=1, \ldots, \mathrm{N}$, where $\mathrm{N}$ is the total number of projects being considered, and $\mathrm{j}=1, \ldots, \mathrm{T}$, when the planning horizon is divided into $\mathrm{T}$ periods.

\section{Objective Function}

Project portfolio selection is usually a multi-objective problem in which objectives in several categories should be maximized or minimized. There are two major problems associated with multi-objective problems which make them difficult to solve. The first is that some of the objectives are qualitative in nature, such as political or environmental objectives, and the second problem is that objectives often conflict with each other. Different techniques are available to help quantify qualitative objectives and to integrate different objectives within one framework. By using these techniques, an overall score can be assigned to each project that reflects its relative contribution. From the many different methods that can be applied to score individual projects, the Analytic Hierarchy Process (AHP) has received wide application in a variety of areas (Golden et al., 1989) and has a 
voluminous body of literature (Zahedi, 1980). In this method, first qualitative and quantitative criteria for selecting projects are identified and integrated into a hierarchical structure; then pairwise comparisons among projects are used to weight the criteria, and finally, based on the amount of benefit contribution of each project to each criteria, the AHP score of individual projects is determined. A higher AHP score reflects a higher project utility. Decision makers may also use other techniques, such as weighted factor scoring (Martino, 1995) that seem more objective or more appealing. For a detailed discussion of these techniques see Archer and Ghasemzadeh (1996a).

Several techniques have been suggested for solving multi-objective zero-one models (Evans, 1984; Rasmussen, 1986). In this paper, however, in order to obviate some of the difficulties and problems associated with pure multiple objective optimization, such as goal programming, we apply a "value function approach" to the problem of maximization of objectives in the various categories. We will also assume the use of a linear additive value function in the model. For a detailed discussion of the value function approach see Evans and Fairbaim (1989).

As a result of the above assumptions, the objective function is given by

Maximize $\mathrm{Z}=\sum_{i=1}^{\mathrm{N}} \sum_{j=1}^{T} a_{i} X_{t}$

where $\mathrm{Z}$ is the value function to be maximized, and $a_{i}$ is the score of project $\mathrm{i}$ (for example, the AHP score) calculated in the previous step. If the organization wants to maximize only a single quantitative objective, such as net present value (NPV), there is no need to score the projects. In this case, $a_{i}$ would be the amount of that criteria, say NPV, that is eamed by project $i$ if it is incorporated in the portfolio. 


\section{Constraints}

The following set of constraints will guarantee that each project, if selected, will not start twice during the planning horizon.

$\sum_{j=1}^{T} X_{i j} \leq 1 \quad$ for $\mathrm{i}=1, \ldots, \mathrm{N}$

A basic assumption is that each project, if started, should continue to completion within the planning horizon. The following set of constraints, that is called project linking, will guarantee the continuation of a project to completion, once it is selected.

$-X_{n 1}+V_{i 11} \leq 0 \quad$ for $\mathrm{i}=1, \ldots, \mathrm{N}$

$-X_{i j}-V_{i(j-1) k}+V_{i j k} \leq 0$

for $i=1, \ldots, N, k+1 \leq j \leq T$, and $k=1, \ldots, T$, and

$\sum_{j=1}^{T} V_{t j k}=D_{i} X_{i k}$

for $i=1, \ldots, N$, and $k=1, \ldots, T$,

$\sum_{k=j+1}^{T} V_{i j k}=0$

for $i=1, \ldots, N$, and $j=1, \ldots, T$, where

$V_{i j k}= \begin{cases}1 & \text { if project } \mathrm{i} \text { starts in period } \mathrm{k} \text { and is active in period } \mathrm{j} \\ 0 & \text { otherwise }\end{cases}$

and $D_{i}$ is the duration of project $i$. 
Appropriate sets of constraints can be established for each limited resource such as finance, work force and machine time. For example, if the total cost to completion of the selected projects should not exceed a certain amount (TC), then the following constraint should be set

$\sum_{i=1}^{N} T C_{i} \sum_{j=1}^{T} X_{j} \leq T C$

where $T C_{i}$ is the total investment required for the completion of project $i$.

The budget available to carry out a set of projects may vary over time. If the planning horizon is divided into $\mathrm{T}$ planning periods, and the maximum allowed cost for all projects during period $\mathrm{j}$ should not exceed a certain amount (TCj), then the set of constraints would be

$\sum_{i=1}^{N} \sum_{k=1}^{j} C_{i j k} V_{j \mathrm{jk}} \leq T C_{j} \quad$ for $\mathrm{j}=1, \ldots, \mathrm{T}$

where $C_{j k}$ is the investment required by project $\mathrm{i}$ in period $\mathrm{j}$ if it starts in period $\mathrm{k}$. More sophisticated cases of resource consumption patterns, such as cases where the cost rate of projects over their execution periods depends on their starting period, can be handled by this set of constraints. As an example, consider a construction project with a duration of three periods (say, three quarters), that needs $5,10,5$ million dollars in each quarter successively if it starts in spring whereas it needs $6,12,7$ million dollars if it starts in fall.

Increased or reduced levels of project funding will normally result in a faster or slower rate of project completion. The same project supported at different levels of funding can be represented as a separate project in the objective function and resource constraints (Bell et al., 1967). The coefficient for this separate project will not be the same in the resource constraints, reflecting the change in the level of funding as well as any difference in the efficiency with which the resource is utilized at the new funding level 
(Jackson, 1983). In such cases, the following constraint must be added to ensure that only one version of the project will be selected

$$
\sum_{i \in S_{v}} \sum_{j=1}^{T} X_{t} \leq 1
$$

where $S_{v}$ is the set that contains different versions of an individual project.

Mandatory projects may exist in the selected portfolio. These are the projects that, based on certain considerations, are to be definitely included in the portfolio. Moreover, at periodic revisions of the portfolio, it is normal for many or all of the ongoing projects to be continued, and therefore must be included in the portfolio. It is important to address the issues of mandatory and ongoing projects in the model because such projects compete with the others for scarce resources and we may want to perform sensitivity analyses that determine the opportunity cost of including them. The following set of constraints guarantees the inclusion of these types of projects in the selected portfolio.

$$
\sum_{j=1}^{T} X_{i j}=1 \quad \text { for } \quad i \in S_{m}
$$

where $S_{m}$ is the set of mandatory projects, and

$$
\sum_{j=1}^{T} X_{i 1}=1 \quad \text { for } \quad i \in S_{0}
$$

where $S_{o}$ is the set of ongoing projects that should be continued. Constraint 12 guarantees that continuing projects should not be interrupted.

The following set of constraints could be used to see the impact of exclusion of certain ongoing projects from the portfolio. This would be useful for sensitivity analysis purpose.

$$
\sum_{j=1}^{T} X_{i j}=0 \quad \text { for } \quad i \in S_{d}
$$


where $S_{d}$ is the set of ongoing projects that should be excluded from the portfolio.

Interdependence among projects is another important issue that must be considered. For example, if project $B$ is dependent on project $A$, then project $A$ must be selected if project B is included in the portfolio. However, project A could be included in the portfolio even if project $B$ is excluded. As an example in the case of information systems projects, the development of an executive support application (ESS) might be dependent on the development or expansion of certain transaction processing applications (TPS) or implementing a certain data warehousing project. These types of interdependencies among projects can be considered in the model by the following sets of constraints

$\sum_{j=1}^{T} X_{i j} \geq \sum_{j=1}^{T} X_{i}$

$\sum_{j=1}^{T} j X_{y}+(T+1) *\left(1-\sum_{j=1}^{T} X_{y}\right)-\sum_{j=1}^{T} j X_{y} \geq D_{i} \sum_{j=1}^{T} X_{y}$

for $i \in P_{l}$, where $P_{l}$ is the set of precursor projects for a particular project $l, l=1, \ldots, \mathrm{L}$.

Constraint 14 guarantees the selection of its precursor projects, once a project is selected, and constraint 15 guarantees that all of the precursor projects will be finished before the successor project starts.

Mutual exclusiveness is another important type of interdependence that should be addressed. A set of projects is considered to be mutually exclusive if we can only include one of its projects in the portfolio. For example, in the case of development projects for joining two different cities, two mutually exclusive projects could be the construction of a highway or a railroad. Once one of these projects is selected the others should be excluded from the portfolio. If there are $P$ sets of mutually exclusive projects, and $S_{p}$ is the pth set of such projects, then the set of constraints is given by 
$\sum_{i \in S,} \sum_{j=1}^{T} X_{i j} \leq 1 \quad$ for $p=1, \ldots, \mathrm{P}$

Many other types of constraints could be added to this model, depending on the situation at hand. For example, one could specify required relationships for different types of projects (e.g., the percent of resources that will be used for each category of projects should not exceed a certain amount, or the number of projects in a certain category must be at least twice the number of projects in another category). As another example, management may prefer a portfolio of projects that balances the overall development risk. Typically, a high-risk project will also have the greatest expected benefits if implemented successfully. For instance, a balanced portfolio might include a small investment in highrisk, high benefit (potential) projects as well as more investment in low-risk projects with more modest expected benefits. A mixture of projects with different risks will allow an organization to achieve acceptable results while taking on some risk in large, unstructured, or relatively high technology projects (Davis and Olson, 1985). This can be done simply by adding the required set of constraints to the model.

Solving the model we have developed will provide a portfolio of projects that maximizes the total benefit of the portfolio and satisfies all the constraints. Moreover, the model determines the period in which each of the selected projects should begin, to satisfy limitations on available resources in each period.

Once the model is solved and a certain solution is obtained, we can examine the robustness of the solution to changes in different variables and parameters of the model by performing sensitivity analysis. For example, we can change the predicted resource consumption, the amount of available resources, or perform other adjustments and observe their impacts on the solution. It should be noted that sensitivity analysis is very critical for integer linear problems because a very small change in one of the coefficients can cause a relatively large change in the solution. Because of the extreme sensitivity of 
the optimal solution to the constraint coefficients in integer programming models, the model should be re-solved several times, with slight variations in the coefficients each time, before attempting to choose an optimal solution for implementation (Anderson et al., 1994). A Decision Support System (DSS) can be applied by decision makers for this purpose. For a detailed discussion on project portfolio selection through a decision support approach see Archer and Ghasemzadeh (1996b).

\section{A case example}

In order to demonstrate the model, we formulated a case example and solved it with the aid of a computer-based optimization package. In this example the decision makers want to select a portfolio of projects from twelve candidate projects and schedule them over a planning horizon that consists of five periods (for example, five years). Information about the case is presented in 39 Tables in the appendix. Table 1 summarizes information on the different candidate projects. Three type of resources: financing, work force and machinery are required for undertaking the projects. Table 2 shows the total financing, man-hours and machine-times available in each period and Tables 3 to 38 show the amount of these resources that projects 1 to 12 consume in each period.

Since in real world situations the amount of resource that is consumed by a project in each period could depend on the starting period of that project, we have considered such a situation in this case. For example, as presented in Table 9, project 3 (with a duration of three periods) requires 300,500 and $300 \mathrm{KS}$ if it starts in period one, 310, 520 , and $310 \mathrm{~K} \$$ if it starts in period 2 and so on. This kind of change in resource consumption could be due to factors such as inflation and seasonal changes.

We used the Windows $₫$ version of the Lingo 8 programming package to solve the developed model. Lingo solves a linear programming relaxation of the problem $\left(0 \leq X_{i} \leq 1 \quad \forall_{i}\right)$ first, and then uses the LP solution to initiate a branch-and-bound 
procedure to find the optimal solution. Table 39 shows the results obtained from applying the optimization model to the example problem. In this table, $X(P 8, T 4)=1$ means that project eight (P8) is selected to be included in the portfolio and should start in period four (T4); $\mathrm{V}(\mathrm{P8}, \mathrm{T} 4, \mathrm{~K} 4)$ and $\mathrm{V}(\mathrm{P} 8, \mathrm{~T} 5, \mathrm{~K} 4)=1$ means that project eight $(\mathrm{P8})$ that starts in period four (K4) will be active in periods four (T4) and five (T5), because it lasts two periods (see Table 1). All other variables (Xs and Vs), for projects that are not selected and not in the table, are zero and have been eliminated from the table to remove the clutter.

Figure 3 presents the results obtained from the model, in a more intuitive and understandable way. This figure shows the selected projects and their start and finish period in a Gantt chart; note that projects not selected are shown as shaded areas at the left of the chart. Figures 4 to 6 represent the amount of each resource that is available and consumed in each period.

It should be noted that although more than one optimal solution might exist in the solution space, depending on the algorithm that is applied by the software program, only one of them will be found. We solved the case example with another optimization software (Cplex (8) that applies a different algorithm and found another optimal solution to the same version of the problem. It was interesting to see that one of the optimal solutions consumed more resources than the other. Such situations are occasionally observed, but one should notice that using less resources in multi-objective problems does not mean that one optimal solution is preferable to another. Since the total scores of both optimal solutions are equal, the use of more resources by one optimal portfolio means that the portfolio is gaining more benefit in one or more categories over the other portfolio.

The proposed optimization model can be incorporated into a DSS in which, first an optimal solution is suggested to decision makers and then the decision makers interact with the system through a suitable interface in order to reach a portfolio more satisfactory 
Figure 3- Selected Project Portfolio and Schedule

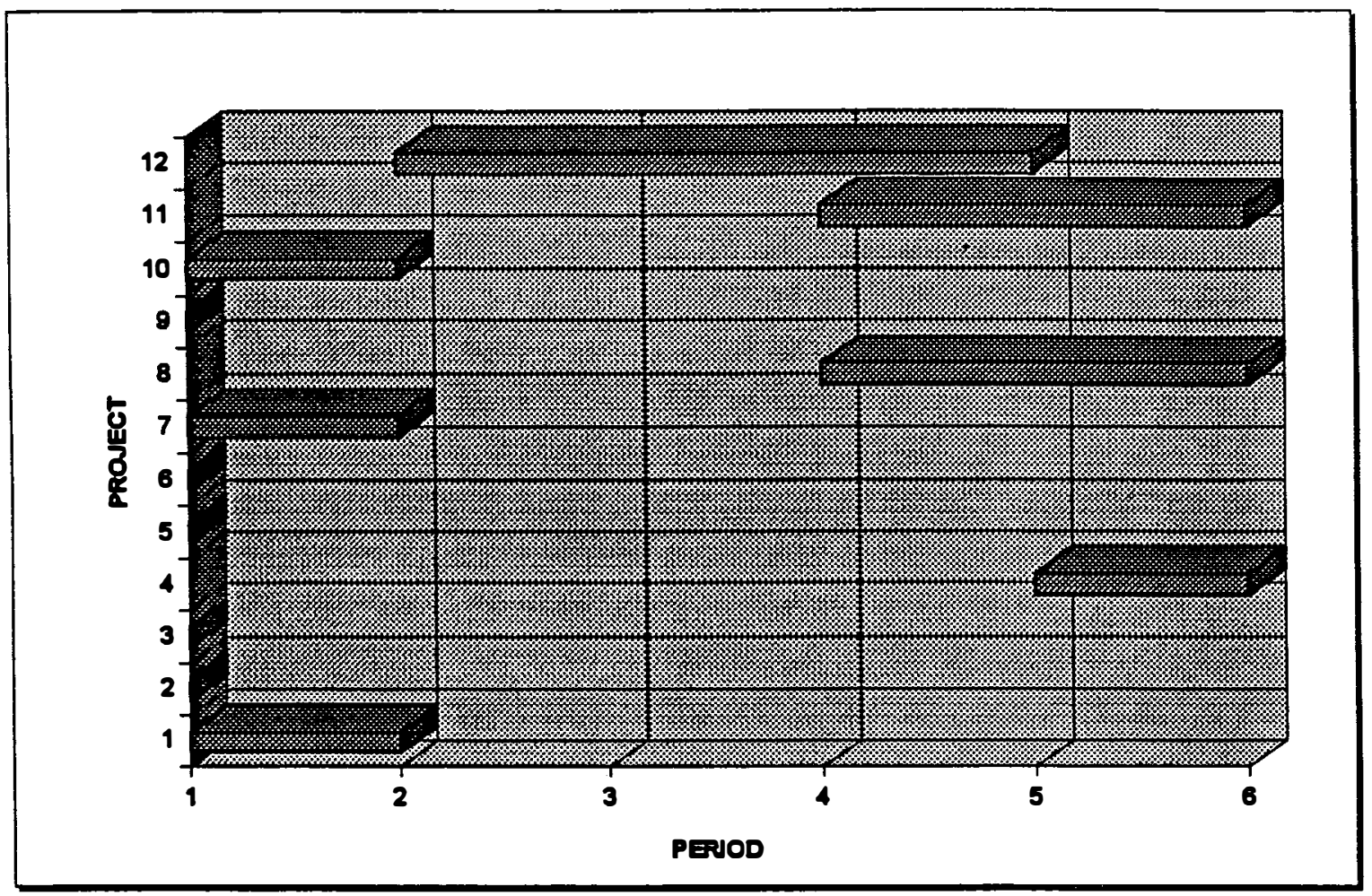

Figure 4- Expenditure in Different Periods

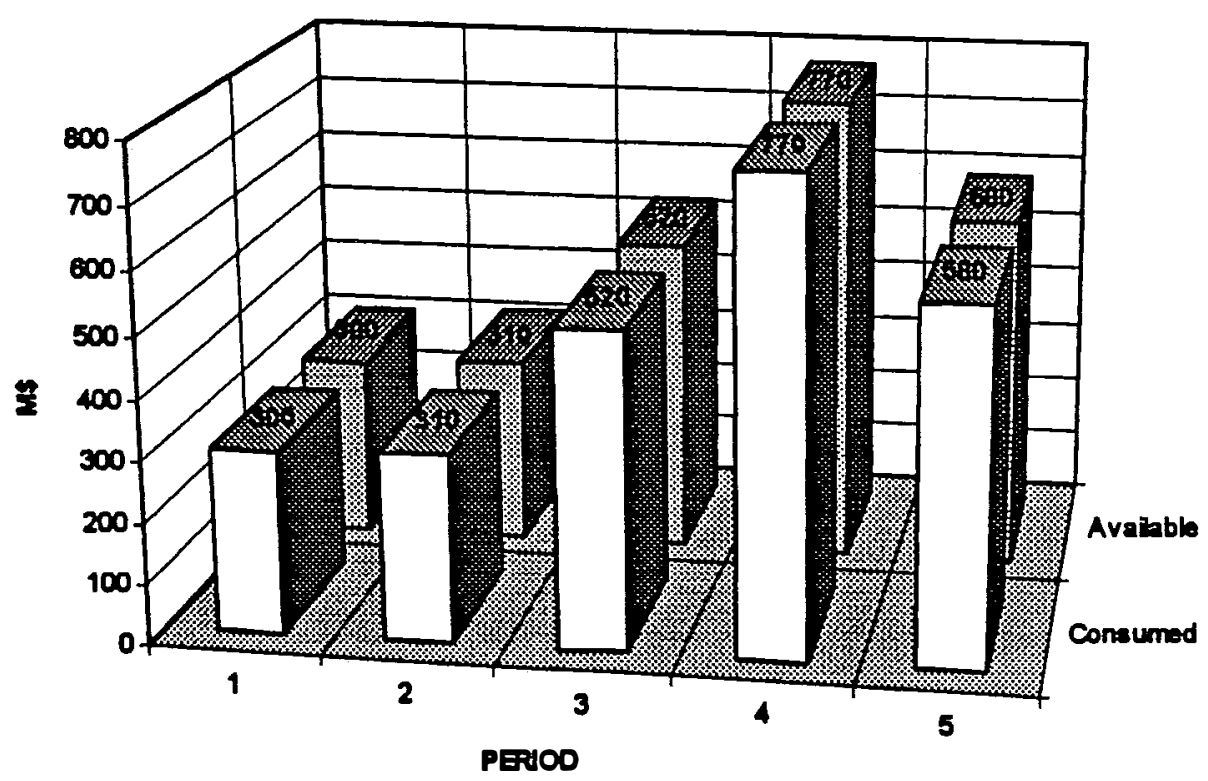


Figure 5- Workforce in Different Periods

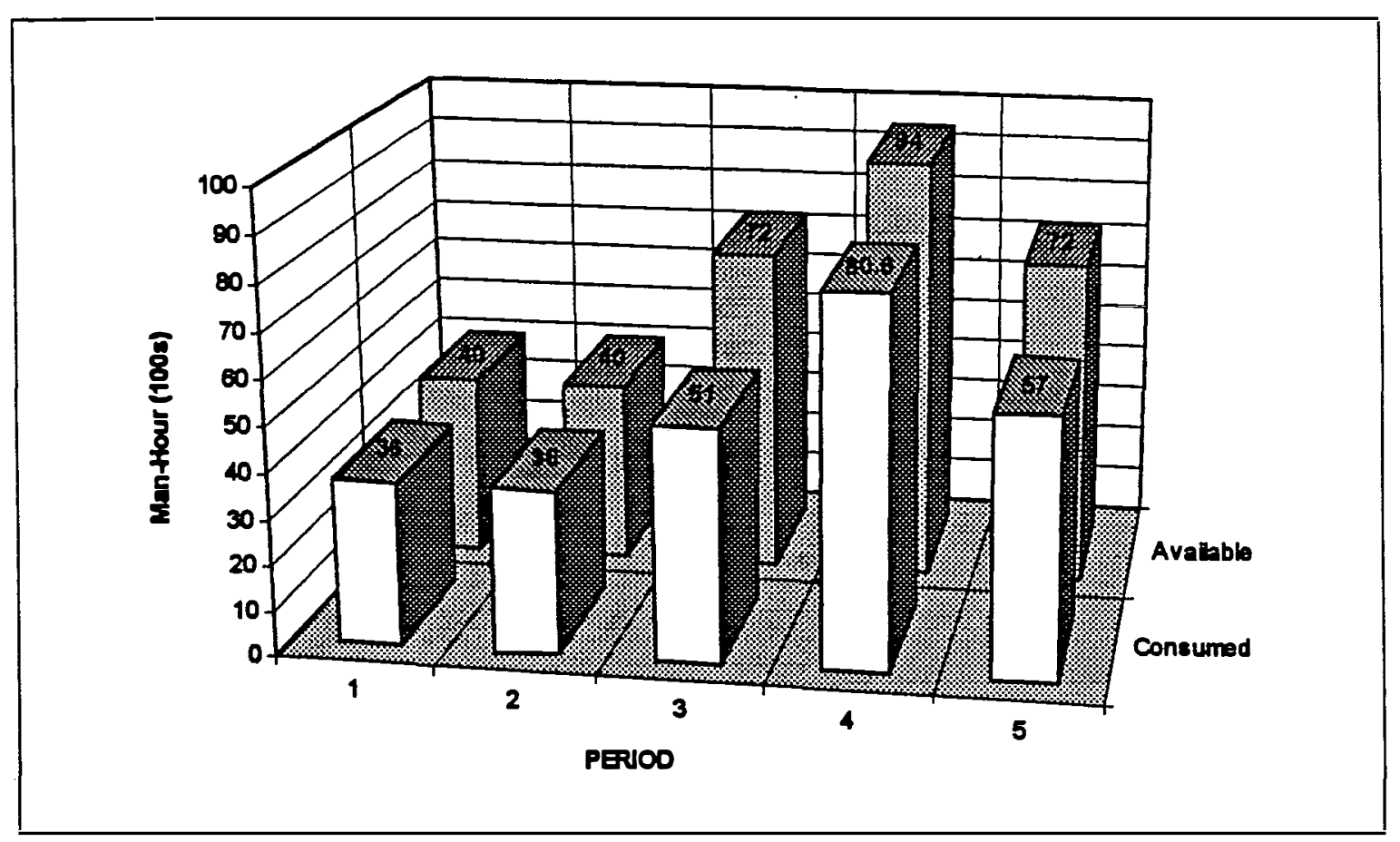

Figure 6- Machine Time in Different Periods

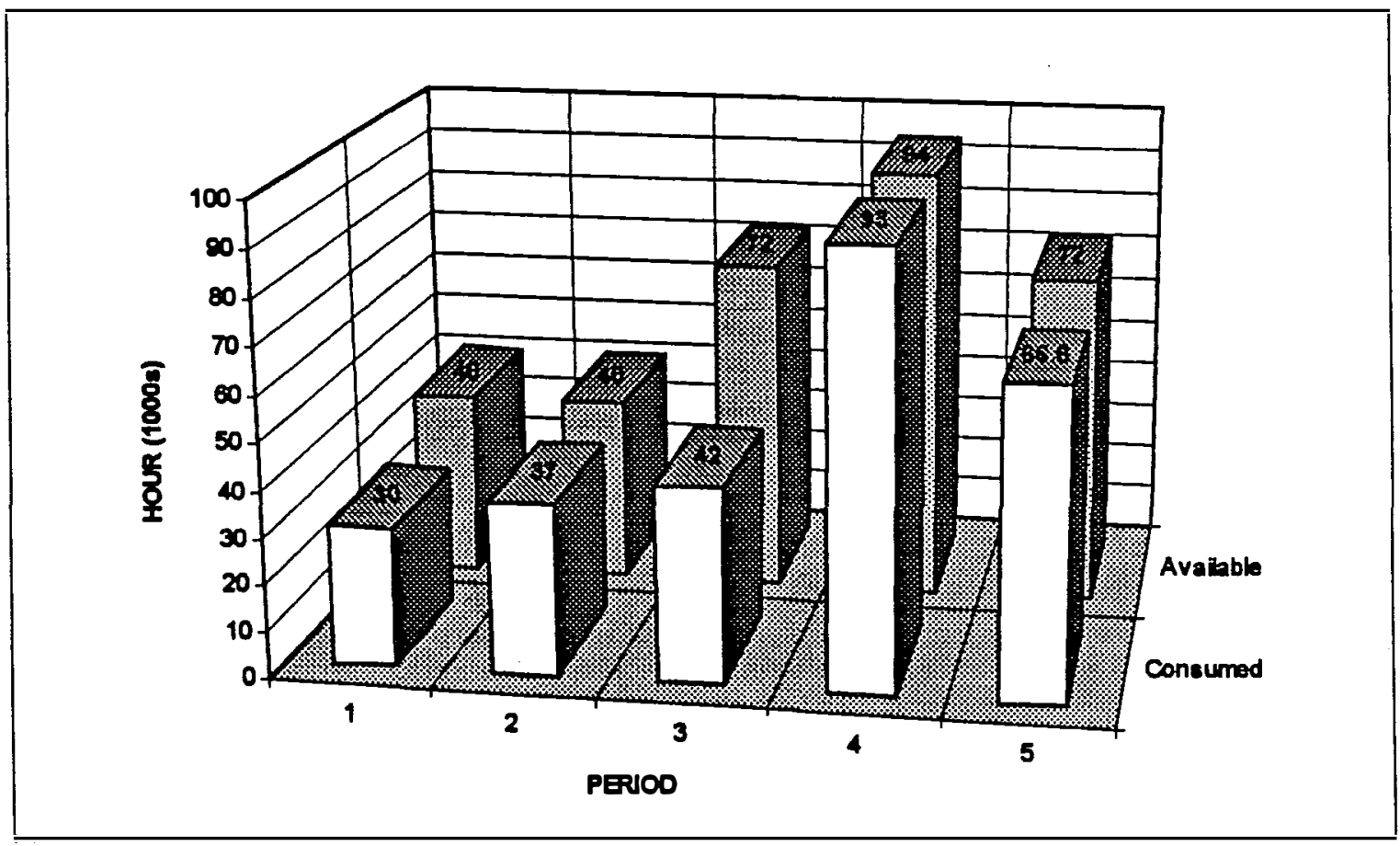


to them. Using the DSS, the decision makers, who are an active element in the decision making process, can perform sensitivity analysis to examine the impact of certain changes (for example, increase in available resources) on the optimal solution. The decision maker can also change the proposed optimal solution, by selecting or de-selecting different projects, to find a more balanced and intuitively appealing portfolio. The DSS also allows the decision maker to observe the impact of any such change on the optimality of the solution.

A prototype DSS that has been developed for this purpose is described in Archer and Ghasemzadeh (1996b).

\section{Summary and discussion}

In this paper, we suggested a zero-one integer linear programming model for project portfolio selection and scheduling. The proposed model addresses the major issues that should be considered in project portfolio selection and finds the global optimal solution to the problem at hand. The major issues that are addressed by the proposed model are: a) existence of multiple, often conflicting objectives, b) existence of both quantitative and quantitative objectives, c) limitations in the required resources (especially when the resource availability and consumption is not uniform over the planning period), d) project interdependencies, e) portfolio balancing in terms of factors that are of importance to decision makers, such as risk and time to complete, and f) project scheduling. The major contributions of the paper are: a) the proposed model not only selects the optimal portfolio but it also schedules the projects based on the available resources in each individual period, and b) it handles time-dependent availability and consumption of resources which frequently occur in real world applications.

The optimal solution recommended by the zero-one IIP model, though very useful, should be treated with caution because the variable and parameter values are 
difficult to estimate. The total score of a portfolio is also not necessarily the sum of individual projects scores as some interactions might exist between different projects, making the linear assumption unrealistic. Research is required to investigate: a) the impact of the accuracy of estimates of input data on the solution and b) the impact of assumptions of linear objective function and linear additive value functions (Evans and Fairbaim, 1989).

The next important issue is that the consequences of projects are not certain and there are different risks, such as technological and marketing risks, associated with each project (for more discussion of uncertainty and risk see McFarlan, 1981; Riggs et al., 1994; Hottenstein and Dean, 1991; and Rousel et al., 1991). The approach that is presented in this paper takes uncertainty and risk into consideration during the scoring stage; it also makes it possible to balance the portfolio in terms of risk by adding a suitable set of constraints to the model, as explained before. The model assumes that the amount of risk for each project is predetermined. However, measurement of risk is a challenging task and research is required to find suitable methods for evaluating project risks.

Another major issue for further research is the failure of traditional optimization techniques in project portfolio selection problems. That is, algorithms should not be used to prescribe solutions without allowing for the judgment, experience, and insight of the decision makers (Mathieu and Gibson, 1993). Project portfolio selection should be considered as a process that includes several steps, rather than just solving an optimization problem. For a detailed discussion of the whole process, in which finding the optimal portfolio is only one step in the whole process, see Archer and Ghasemzadeh (1996a).

Provision for continuous interaction between the system and decision makers throughout the whole process of project portfolio selection is important because: 1) it is extremely difficult to formulate explicitly in advance all the preferences of decision maker, 2) involvement of decision makers in the selection process indirectly motivates successful implementation of the selected projects, and 3) interactive decision making has been accepted as the most appropriate way of obtaining the correct preferences of decision 
makers (Mukherjee, 1994). In order to increase the likelihood of user acceptability, research is required to determine the important aspects of such a DSS including a) definition of the characteristics and features of decision support system for project portfolio selection, b) the type of support that should be provided at each step of the process, c) sensitivity-analysis techniques that should be used within the process, d) the major components of the DSS (i.e., model management, data management, the user interface, and their interactions), and e) the selection of suitable software modules that perform the different tasks in portfolio selection efficiently and effectively and that can interact in a seamless manner. The DSS should not be limited to a specific decision application and its model management subsystem should have the capability of supporting decision makers in selecting and/or formulating the required models for the specific application at hand through interactive sessions, without requiring user to have a high degree of technical expertise.

\section{References}

Anderson, D.R., Sweeney, D.J. and Williams T.A. (1994), "An Introduction to Management Science: Quontitative Approaches to Decision Making", West Publishing Co., NY.

Archer, N.P. and Ghasemzadeh, F. (1996a), "Project portfolio selection techniques: A review and a suggested integrated approach", Innovation Research Center Working Paper 46, Hamilton. Ont.: Michael G. DeGroote School of Business, McMaster University.

Archer, N.P. and Ghasemzadeh, F. (1996b), "Project portfolio selection management through decision support: a system prototype", Innovation Research Center Working Paper 49, Hamilton. Ont.: Michael G. DeGroote School of Business, McMaster University.

Bell, D.C., Chilcott, J.E., Read, A.W., and Salway, R.A. (1967), "Application of a research project selection method in the North Eastern Region Scientific Service Department", Central Electricity Generating Board Report RH/H/R2, UK.

Davis, G.B. and Olson, M.H. (1985), Management Information Systems, New York, NY: McGraw-Hill. 
Dos Santos, B.L. (1989), "Selecting information system projects: problems, solutions and challenges", Proceedings of the Hawaii Conference on System Sciences.

Evans, G.W., (1984), "An overview of techniques for solving multi-objective mathematical programs", Management Science, 30/11, 1268-1282.

Evans, G.W. and Fairbaim, R. (1989), "Selection and scheduling of advanced missions for NASA using 0-1 integer linear programming", Journal of the Operational Research Society, 40/11, 971-981.

Golden, B.L., Wasil, E.A., and Levy, D.E. (1989), “Applications of the analytic hierarchy process: A categorized, annotated bibliography". Published in The Analytic Hierarchy Process: Applications and Studies (Edited by Golden, B.L., Wasil, E.A., and Harker, P.T.).

Hottenstein, M.P. and Dean J.W. (1991), "Managing risk in advanced manufacturing technology", California Management Review, 34, 112-126.

Jackson, B. (1983), "Decision methods for selecting a portfolio of R\&D projects", Research Management, September-October, 21-26.

Kira, D.S., Kusy, M.I, Murray, D.H., and Goranson B.J. (1990), "A Specific Decision Support System (SDSS) to develop an optimal project portfolio mix under uncertainty", IEEE Transactions On Engineering Management, 37/3, 213-221.

Martino J.P. (1995), Research and Development Project Selection, New York, NY: John Wiley \& Sons Inc.

Mathieu, R.G. and Gibson, J.E. (1993), "A methodology for large scale R\&D planning based on cluster analysis", IEEE Transactions On Engineering Management, 30/3, 283291.

McFarlan, F. W. (1991), "Portfolio approach to information systems", Harvard Business Review, 59/5, 142-150.

Mukherjee, K. (1994), "Application of interactive method for MOLIP in project selection decisions: A case of Indian coal mining industry", International Journal of Production Economics, 36, 203-211.

Nicholas, J.M. (1990) Managing Business and Engineering Projects: Concepts \& Implementation, Prentice Hall.

Rasmussen, L.M. (1986), "Zero-one programming with multiple criteria", European Journal of Operational Research, 26, 83-95. 
Riggs, J. L., Brown S.B., and Trueblood, R.P. (1994), "Integration of technical, cost and schedule risks in project management", Computers and Operations Research. 21/5, 521533.

Rousel, P.A., Saad, K.N., and Erickson, T.J. (1991), Third Generation R\&D, Cambridge, MA: Harvard Business School Press.

Schniederjans, M. and Santhanam, R (1993), "A multi-objective constrained resource information system project selection method", European Joumal of Operational Research. 70, 244-253.

Zahedi Fatemeh (1986), "The analytic hierarchy process - A survey of the method and its applications", Interfaces, 16/4, 96-108. 
Appendix 
Table 1- Project Information

\begin{tabular}{|c|c|c|c|c|}
\hline Proct & scorom & $\begin{array}{l}\text { Dowratron } \\
(\text { Portods }\end{array}$ & 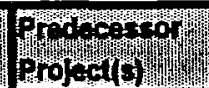 & 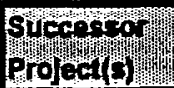 \\
\hline 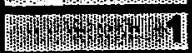 & 10 & & - & 3 \\
\hline myry & 20 & & - & - \\
\hline 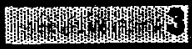 & 30 & & 1 & - \\
\hline 型 & 40 & & - & - \\
\hline 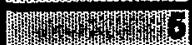 & 50 & & - & - \\
\hline 物 & 60 & & - & $\begin{array}{c}- \\
-\end{array}$ \\
\hline WWW & 70 & & - & - \\
\hline 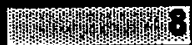 & 80 & & - & - \\
\hline 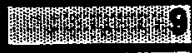 & 90 & & - & - \\
\hline 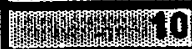 & 100 & & - & - \\
\hline MFAm & 110 & & - & - \\
\hline 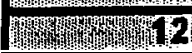 & 120 & & - & - \\
\hline
\end{tabular}

Table 2- Total Resources Available

\begin{tabular}{|c|c|c|c|c|c|}
\hline & $x_{4}^{4}$ & 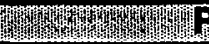 & 00 & & \\
\hline 10 & WI! & 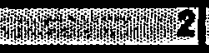 & 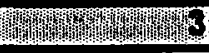 & 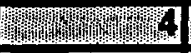 & m \\
\hline Honey & 300 & 3 & 520 & 770 & \\
\hline Manthours & 4000 & 4000 & 7200 & 9400 & \\
\hline Vachine & 40000 & 40000 & 72000 & 94000 & 720 \\
\hline
\end{tabular}


Table 3- Project 1 Financial Requirements

\begin{tabular}{|c|c|c|c|c|c|}
\hline \multirow{2}{*}{ Startingm } & \multicolumn{5}{|c|}{ Why } \\
\hline & WXWWWI & 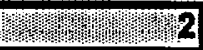 & 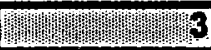 & 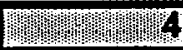 & 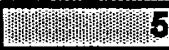 \\
\hline 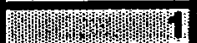 & 100 & 0 & 0 & 0 & 0 \\
\hline 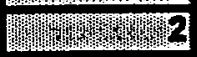 & 0 & 105 & 0 & $\overline{0}$ & $\overline{0}$ \\
\hline 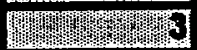 & $\overline{0}$ & 0 & $\overline{110}$ & $\overline{0}$ & $\overline{0}$ \\
\hline Prem & 0 & 0 & 0 & $\overline{115}$ & 0 \\
\hline 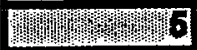 & 0 & 0 & 0 & 0 & 120 \\
\hline
\end{tabular}

Table 4- Project 1 Workforce Requirements

\begin{tabular}{|c|c|c|c|c|c|}
\hline \multirow{2}{*}{$\begin{array}{l}\text { Startipd } \\
\text { Pertod }\end{array}$} & \multicolumn{5}{|c|}{ 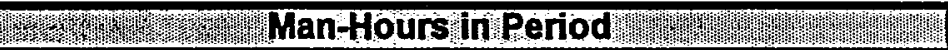 } \\
\hline & 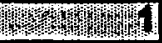 & (1) & 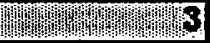 & 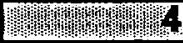 & 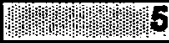 \\
\hline 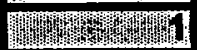 & 1200 & 0 & 0 & 0 & 0 \\
\hline 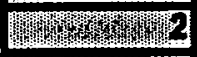 & 0 & 1210 & 0 & 0 & 0 \\
\hline m & $\mathbf{0}$ & 0 & 1220 & 0 & 0 \\
\hline MWW & 0 & 0 & 0 & 1230 & $\mathbf{0}$ \\
\hline 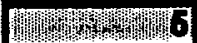 & 0 & $\mathbf{0}$ & 0 & 0 & 1240 \\
\hline
\end{tabular}

Table 5- Project 1 Machinery Requirements

\begin{tabular}{|c|c|c|c|c|c|}
\hline $\begin{array}{l}\text { Starting } \\
\text { Period }\end{array}$ & 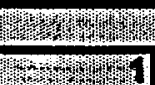 & 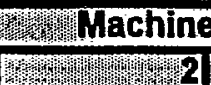 & Hours inPe & 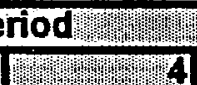 & mymming \\
\hline WWWWWWWI & 10000 & 0 & 0 & 0 & 0 \\
\hline WWWWWW & 0 & 10200 & 0 & 0 & 0 \\
\hline menterym & $\overline{0}$ & 0 & 10400 & 0 & $\overline{0}$ \\
\hline 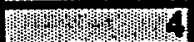 & 0 & $\overline{0}$ & $\overline{0}$ & 10500 & 0 \\
\hline 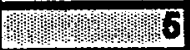 & $\overline{0}$ & 0 & $\overline{0}$ & 0 & 10600 \\
\hline
\end{tabular}


Table 6- Project 2 Financial Requirements

\begin{tabular}{|c|c|c|c|c|c|}
\hline \multirow{2}{*}{$\begin{array}{l}\text { Starting } \\
\text { pertod }\end{array}$} & \multicolumn{5}{|c|}{ WW Why } \\
\hline & WWWr & mpmem & MmW & 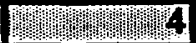 & mimms \\
\hline 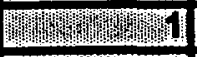 & 200 & 200 & 0 & 0 & 0 \\
\hline 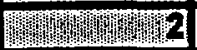 & 0 & 210 & 210 & $\mathbf{0}$ & 0 \\
\hline WITWM & 0 & 0 & 220 & 220 & 0 \\
\hline N7mp & 0 & 0 & 0 & 230 & 230 \\
\hline mWMma & $\overline{0}$ & $\overline{0}$ & 0 & 0 & 0 \\
\hline
\end{tabular}

Table 7- Project 2 Workforce Requirements

\begin{tabular}{|c|c|c|c|c|c|}
\hline \multirow{2}{*}{$\begin{array}{l}\text { Starting } \\
\text { Period }\end{array}$} & \multicolumn{5}{|c|}{ 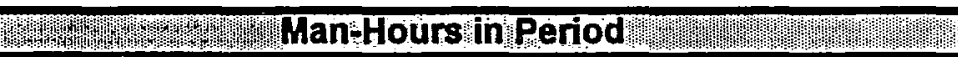 } \\
\hline & 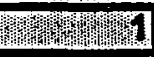 & 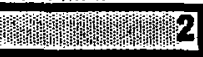 & Mmmman:m & 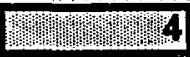 & 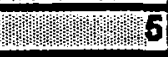 \\
\hline 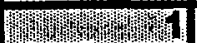 & 2200 & 2200 & $\overline{0}$ & 0 & 0 \\
\hline WII) & 0 & 2210 & 2210 & 0 & $\overline{0}$ \\
\hline 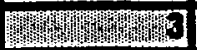 & $\overline{0}$ & 0 & 2220 & 2220 & $\overline{0}$ \\
\hline WmmW & 0 & 0 & 0 & 2230 & 2230 \\
\hline 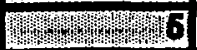 & 0 & 0 & $\overline{0}$ & 0 & 0 \\
\hline
\end{tabular}

Table 8- Project 2 Machinery Requirements

\begin{tabular}{|c|c|c|c|c|c|}
\hline \multirow{2}{*}{$\begin{array}{l}\text { Starting } \\
\text { Pertod }\end{array}$} & \multicolumn{5}{|c|}{ 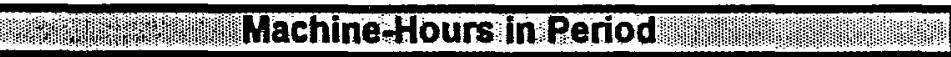 } \\
\hline & 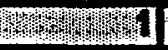 & 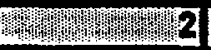 & 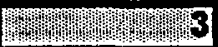 & 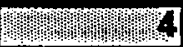 & mim:mims \\
\hline 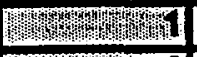 & 25000 & 25000 & $\begin{array}{r}0 \\
\end{array}$ & 0 & 0 \\
\hline 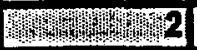 & 0 & 26000 & 26000 & 0 & $\overline{0}$ \\
\hline Whymen & 0 & 0 & 27000 & 27000 & 0 \\
\hline WIF & 0 & 0) & 0 & 28000 & 28000 \\
\hline Wrimpinas & 0 & 0 & 0 & 0 & 0 \\
\hline
\end{tabular}


Table 9- Project 3 Financial Requirements

\begin{tabular}{|c|c|c|c|c|c|}
\hline \multirow{2}{*}{$\begin{array}{l}\text { Stantipd } \\
\text { Penod }\end{array}$} & \multicolumn{5}{|c|}{ 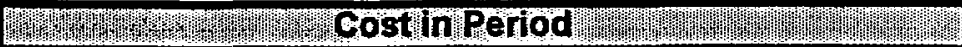 } \\
\hline & 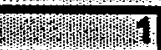 & WWIVIN & 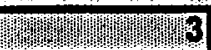 & 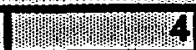 & 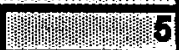 \\
\hline 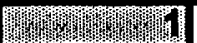 & 300 & 500 & 300 & 0 & 0 \\
\hline 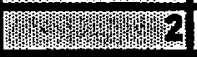 & 0 & 310 & 520 & 310 & 0 \\
\hline 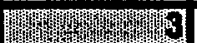 & $\overline{0}$ & 0 & 320 & 540 & 320 \\
\hline 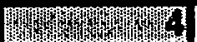 & 0 & $\mathbf{0}$ & 0 & $\mathbf{0}$ & 0 \\
\hline mWman & 0 & 0 & $\overline{0}$ & $\overline{0}$ & 0 \\
\hline
\end{tabular}

Table 10- Project 3 Workforce Requirements

\begin{tabular}{|c|c|c|c|c|c|}
\hline \multirow{2}{*}{ Starfing } & \multicolumn{5}{|c|}{ 37m } \\
\hline & 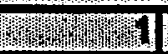 & 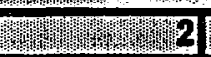 & WM & WWWW WW WW & 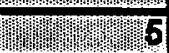 \\
\hline 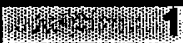 & 3500 & 5000 & 3500 & 0 & 0 \\
\hline 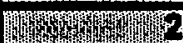 & 0 & 3600 & 5100 & 3600 & $\overline{0}$ \\
\hline W & 0 & 0 & 3700 & 5200 & 3700 \\
\hline 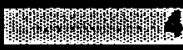 & 0 & 0 & 0 & 0 & 0 \\
\hline 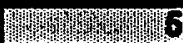 & 0 & 0 & 0 & 0 & 0 \\
\hline
\end{tabular}

Table 11- Project 3 Machinery Requirements

\begin{tabular}{|c|c|c|c|c|c|}
\hline \multirow{2}{*}{$\begin{array}{l}\text { Starting } \\
\text { Penodm }\end{array}$} & \multicolumn{5}{|c|}{ 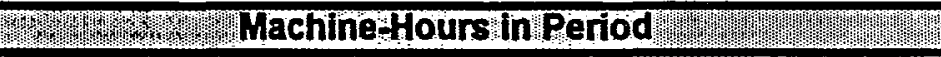 } \\
\hline & WW"Wr & WWWWWWT2 & 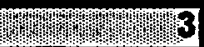 & 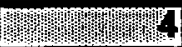 & 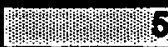 \\
\hline 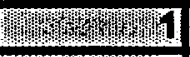 & 35000 & 40000 & 35000 & 0 & 0 \\
\hline 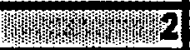 & 0 & 37000 & 42000 & 37000 & 0 \\
\hline 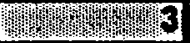 & 0 & 0 & 39000 & 45000 & 39000 \\
\hline 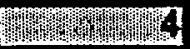 & 0 & 0 & 0 & 0 & $\mathbf{0}$ \\
\hline Wmamp & 0 & 0 & 0 & $\overline{0}$ & 0 \\
\hline
\end{tabular}


Table 12- Project 4 Financial Requirements

\begin{tabular}{|c|c|c|c|c|c|}
\hline \multirow{2}{*}{$\begin{array}{l}\text { Btaring } \\
\text { Period }\end{array}$} & \multicolumn{5}{|c|}{ 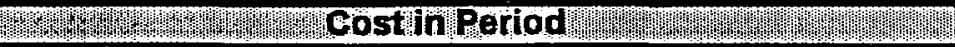 } \\
\hline & WPImI & MIIm:MIn: & 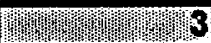 & 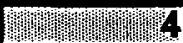 & 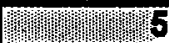 \\
\hline mWmW & 100 & 0 & $\mathbf{0}$ & 0 & 0 \\
\hline 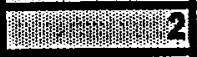 & 0 & 105 & 0 & $\overline{0}$ & 0 \\
\hline mm & 0 & 0 & 110 & $\mathbf{0}$ & 0 \\
\hline mam & $\mathbf{0}$ & 0 & $\mathbf{0}$ & 115 & $\mathbf{0}$ \\
\hline MmmmW" & $\mathbf{0}$ & $\overline{0}$ & $\mathbf{0}$ & 0 & 120 \\
\hline
\end{tabular}

Table 13-Project 4 Workforce Requirements

\begin{tabular}{|c|c|c|c|c|c|}
\hline \multirow{2}{*}{ Starting } & \multicolumn{5}{|c|}{ 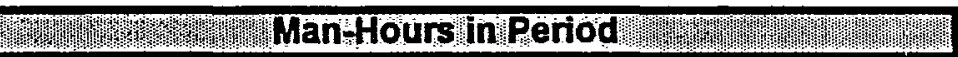 } \\
\hline & 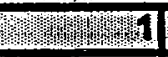 & 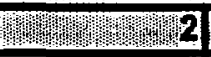 & 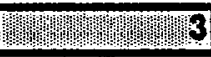 & 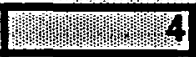 & 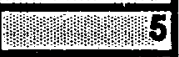 \\
\hline WWymm & 1200 & 0 & 0 & 0 & 0 \\
\hline 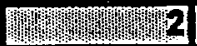 & 0 & 1210 & $\overline{0}$ & 0 & $\overline{0}$ \\
\hline MWWW & $\mathbf{0}$ & 0 & 1220 & 0 & 0 \\
\hline 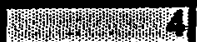 & 0 & 0 & 0 & 1230 & 0 \\
\hline 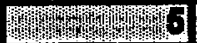 & 0 & 0 & 0 & 0 & 1240 \\
\hline
\end{tabular}

Table 14- Project 4 Machinery Requirements

\begin{tabular}{|c|c|c|c|c|c|}
\hline \multirow{2}{*}{$\begin{array}{l}\text { Stanting } \\
\text { Period }\end{array}$} & \multicolumn{5}{|c|}{ 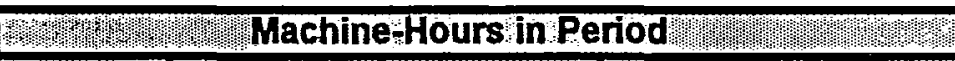 } \\
\hline & 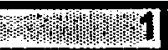 & 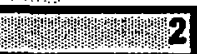 & Wminmminm & 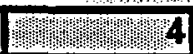 & 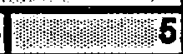 \\
\hline 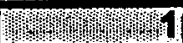 & 10000 & 0 & 0 & 0 & 0 \\
\hline 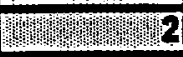 & 0 & 10200 & 0 & 0 & 0 \\
\hline 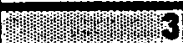 & 0 & 0 & 10400 & 0 & 0 \\
\hline 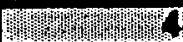 & 0 & 0 & 0 & 10500 & 0 \\
\hline 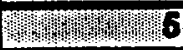 & 0 & 0 & $\overline{0}$ & 0 & 10600 \\
\hline
\end{tabular}


Table 15- Project 5 Financial Requirements

\begin{tabular}{|c|c|c|c|c|c|}
\hline spring & 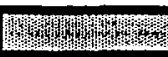 & 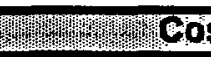 & thilleriod & 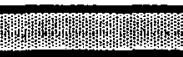 & 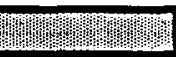 \\
\hline Pronodm & 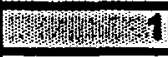 & 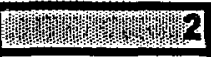 & 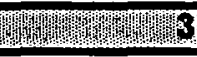 & 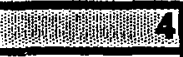 & 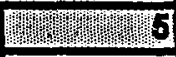 \\
\hline mmmmm & 200 & 200 & 0 & 0 & 0 \\
\hline W17W & 0 & 210 & 210 & 0 & 0 \\
\hline mIm) & 0 & 0 & 220 & 220 & 0 \\
\hline WW & $\overline{0}$ & 0 & $\overline{0}$ & 230 & 230 \\
\hline Whary & $\overline{0}$ & 0 & 0 & 0 & $\overline{0}$ \\
\hline
\end{tabular}

Table16- Project 5 Workforce Requirements

\begin{tabular}{|c|c|c|c|c|c|}
\hline \multirow{2}{*}{ Starting } & \multicolumn{5}{|c|}{ 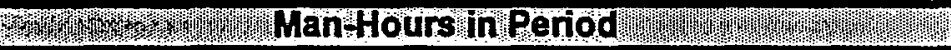 } \\
\hline & 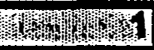 & 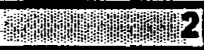 & 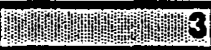 & 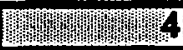 & 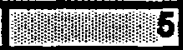 \\
\hline 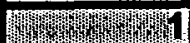 & 2200 & 2200 & 0 & $\mathbf{0}$ & 0 \\
\hline Mym & 0 & 2210 & 2210 & $\mathbf{0}$ & 0 \\
\hline 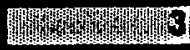 & 0 & 0 & 2220 & 2220 & 0 \\
\hline 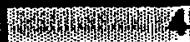 & $\mathbf{0}$ & $\mathbf{0}$ & 0 & 2230 & 2230 \\
\hline 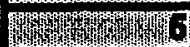 & 0 & $\mathbf{0}$ & 0 & 0 & 0 \\
\hline
\end{tabular}

Table 17- Project 5 Machinery Requirements

\begin{tabular}{|c|c|c|c|c|c|}
\hline \multirow{2}{*}{$\begin{array}{l}\text { Starting } \\
\text { Penod }\end{array}$} & \multicolumn{5}{|c|}{ 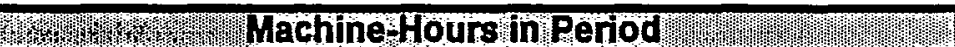 } \\
\hline & Wrown & WWm & 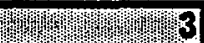 & 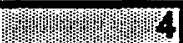 & min:min \\
\hline 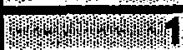 & 25000 & 25000 & 0 & 0 & 0 \\
\hline PVIn: & 0 & 26000 & 26000 & 0 & $\overline{0}$ \\
\hline Whytry & 0 & 0 & 27000 & 27000 & $\overline{0}$ \\
\hline 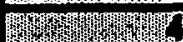 & 0 & 0 & 0 & 28000 & 28000 \\
\hline 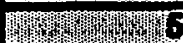 & o & $\overline{0}$ & $\overline{0}$ & $\mathbf{0}$ & $\overline{0}$ \\
\hline
\end{tabular}


Table 18- Project 6 Financial Requirements

\begin{tabular}{|c|c|c|c|c|c|}
\hline \multirow{2}{*}{$\begin{array}{l}\text { Starting } \\
\text { Period }\end{array}$} & \multicolumn{5}{|c|}{ Pry } \\
\hline & WTWII & mimman & 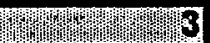 & minmmin & 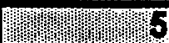 \\
\hline FWm: & 300 & 500 & 300 & 0 & 0 \\
\hline 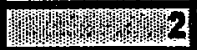 & 0 & 310 & 520 & 310 & 0 \\
\hline 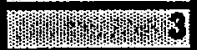 & $\overline{0}$ & 0 & 320 & 540 & 320 \\
\hline 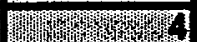 & $\overline{0}$ & $\overline{0}$ & 0 & 0 & 0 \\
\hline m & $\overline{0}$ & $\overline{0}$ & $\overline{0}$ & $\overline{0}$ & $\mathbf{0}$ \\
\hline
\end{tabular}

Table 19- Project 6 Workforce Requirements

\begin{tabular}{|c|c|c|c|c|c|}
\hline \multirow{2}{*}{$\begin{array}{l}\text { Starting } \\
\text { Period }\end{array}$} & \multicolumn{5}{|c|}{ 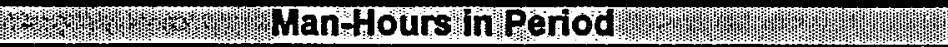 } \\
\hline & 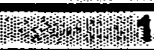 & 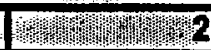 & 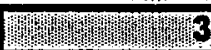 & 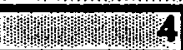 & 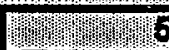 \\
\hline 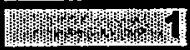 & 3500 & 5000 & 3500 & 0 & 0 \\
\hline MTM & $\mathbf{0}$ & 3600 & 5100 & $\overline{3600}$ & $\overline{0}$ \\
\hline MWTW & 0 & 0 & 3700 & 5200 & 3700 \\
\hline 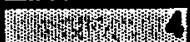 & $\mathbf{0}$ & $\overline{0}$ & $\mathbf{0}$ & $\overline{0}$ & 0 \\
\hline WmW & $\mathbf{0}$ & $\mathbf{0}$ & $\mathbf{0}$ & $\mathbf{0}$ & 0 \\
\hline
\end{tabular}

Table 20- Project 6 Machinery Requirements

\begin{tabular}{|c|c|c|c|c|c|}
\hline \multirow{2}{*}{$\begin{array}{l}\text { Starting } \\
\text { Period }\end{array}$} & \multicolumn{5}{|c|}{ 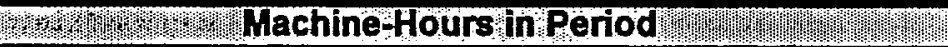 } \\
\hline & "X: & 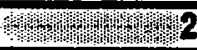 & 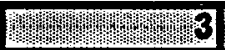 & 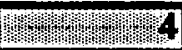 & 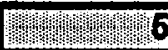 \\
\hline MIITWW1: & 35000 & 40000 & 35000 & 0 & $\mathbf{0}$ \\
\hline 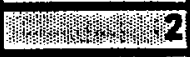 & 0 & 37000 & 42000 & 37000 & 0 \\
\hline WWWWW & $\overline{0}$ & 0 & 39000 & 45000 & 39000 \\
\hline Wmantwa & 0 & $\mathbf{0}$ & 0 & $\mathbf{0}$ & 0 \\
\hline 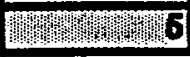 & 0 & 0 & 0 & 0 & 0 \\
\hline
\end{tabular}


Table 21- Project 7 Financial Requirements

\begin{tabular}{|c|c|c|c|c|c|}
\hline \multirow{2}{*}{ String } & \multicolumn{5}{|c|}{ 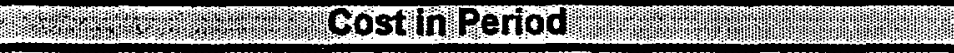 } \\
\hline & WIXW & 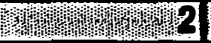 & 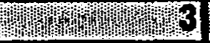 & WWWWWM & WWWWWWE \\
\hline 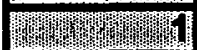 & 100 & 0 & 0 & 0 & 0 \\
\hline 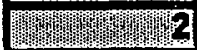 & 0 & 105 & 0 & 0 & $\overline{0}$ \\
\hline 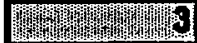 & 0 & 0 & 110 & 0 & 0 \\
\hline 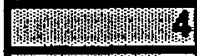 & 0 & 0) & 0 & 115 & 0 \\
\hline 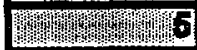 & 0 & 0] & 0 & 0 & 120 \\
\hline
\end{tabular}

Table 22- Project 7 Workforce Requirements

\begin{tabular}{|c|c|c|c|c|c|}
\hline \multirow{2}{*}{$\begin{array}{l}\text { Statino } \\
\text { Ponod } \\
\text { Pom }\end{array}$} & \multicolumn{5}{|c|}{ WWW } \\
\hline & 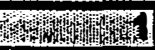 & Wha & 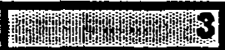 & Whe & 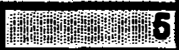 \\
\hline 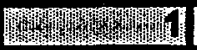 & 1200 & 0 & 0 & 0 & 0 \\
\hline 17ma & 0 & 1210 & 0 & 0 & 0 \\
\hline 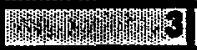 & 0 & 0 & 1220 & 0 & 0 \\
\hline Wmy & 0 & 0 & 0 & 1230 & 0 \\
\hline W"W & 0 & 0 & 0 & 0 & 1240 \\
\hline
\end{tabular}

Table 23- Project 7 Machinery Requirements

\begin{tabular}{|c|c|c|c|c|c|}
\hline \multirow{2}{*}{ Startingm } & \multicolumn{5}{|c|}{ 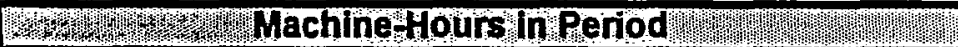 } \\
\hline & 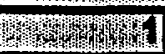 & 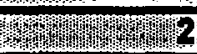 & WWTH & WMWWW & WMPNW \\
\hline WMWmin: & 10000 & 0 & 0 & 0 & 0 \\
\hline 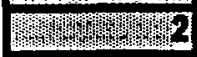 & 0 & 10200 & 0 & $\overline{0}$ & 0 \\
\hline 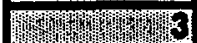 & $\overline{0}$ & 0 & 10400 & $\overline{0}$ & $\overline{0}$ \\
\hline 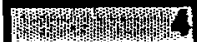 & 0 & 0 & 0 & 10500 & 0 \\
\hline 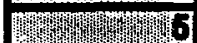 & $\overline{0}$ & $\mathbf{0}$ & $\overline{0}$ & 0 & 10600 \\
\hline
\end{tabular}


Table 24- Project 8 Financial Requirements

\begin{tabular}{|c|c|c|c|c|c|}
\hline \multirow{2}{*}{ Sterting } & \multicolumn{5}{|c|}{ WWm } \\
\hline & 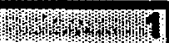 & 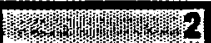 & 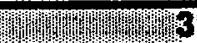 & 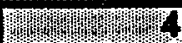 & minmments \\
\hline 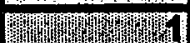 & 200 & 200 & 0 & $\mathbf{0}$ & $\overline{0}$ \\
\hline 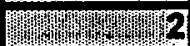 & 0 & 210 & 210 & $\overline{0}$ & $\overline{0}$ \\
\hline 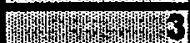 & 0 & 0 & 220 & 220 & 0 \\
\hline 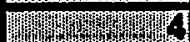 & $\overline{0}$ & $\overline{0}$ & 0 & 230 & 230 \\
\hline my & $\overline{0}$ & $\mathbf{0}$ & $\mathbf{0}$ & $\mathbf{0}$ & $\overline{0}$ \\
\hline
\end{tabular}

Table 25- Project 8 Workforce Requirements

\begin{tabular}{|c|c|c|c|c|c|}
\hline Starfinn & 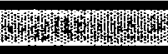 & 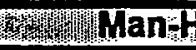 & lours Tin Reric & id) & 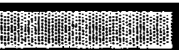 \\
\hline Pedod d & 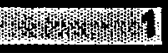 & 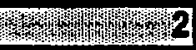 & 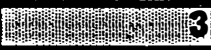 & 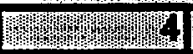 & 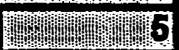 \\
\hline MmWrym & 2200 & 2200 & $\mathbf{0}$ & 0 & 0 \\
\hline 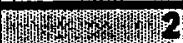 & 0 & 2210 & 2210 & 0 & 0 \\
\hline 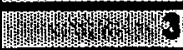 & 0 & 0 & 2220 & 2220 & 0) \\
\hline 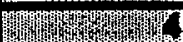 & $\overline{0}$ & $\overline{0}$ & 0 & 2230 & 2230 \\
\hline Premp & 0 & 0 & 0 & 0 & 0 \\
\hline
\end{tabular}

Table 26- Project 8 Machinery Requirements

\begin{tabular}{|c|c|c|c|c|c|}
\hline \multirow{2}{*}{$\begin{array}{l}\text { Startifymm } \\
\text { Penod }\end{array}$} & \multicolumn{5}{|c|}{ 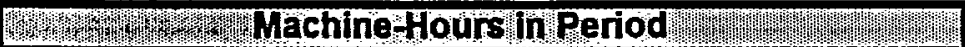 } \\
\hline & 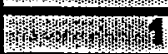 & 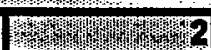 & 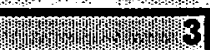 & 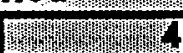 & WmPrym \\
\hline 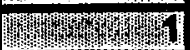 & 25000 & 25000 & 0 & 0 & 0 \\
\hline 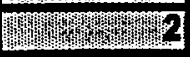 & 0 & 26000 & 26000 & 0 & 0 \\
\hline 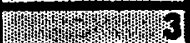 & $\mathbf{0}$ & $\mathbf{0}$ & 27000 & 27000 & $\overline{0}$ \\
\hline MWw & 0 & $\overline{0}$ & 0 & 28000 & 28000 \\
\hline 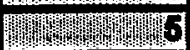 & 0 & $\overline{0}$ & 0 & 0 & 0 \\
\hline
\end{tabular}


Table 27- Project 9 Financial Requirements

\begin{tabular}{|c|c|c|c|c|c|}
\hline \multirow{2}{*}{$\begin{array}{l}\text { Stanting } \\
\text { Reriod }\end{array}$} & \multicolumn{5}{|c|}{ Cost in Reriod } \\
\hline & WmWmint & & 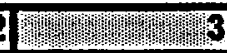 & DImIn & Din:W:5 \\
\hline 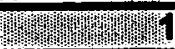 & 300 & 500 & 300 & 0 & 0 \\
\hline 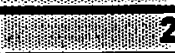 & 0 & $\overline{310}$ & 520 & 310 & $\overline{0}$ \\
\hline 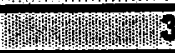 & 0 & 0 & $\overline{320}$ & 540 & 320 \\
\hline 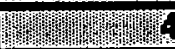 & $\overline{0}$ & $\overline{0}$ & 0 & 0 & 0 \\
\hline 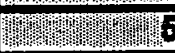 & $\mathbf{0}$ & $\overline{0}$ & $\overline{0}$ & $\overline{0}$ & $\overline{0}$ \\
\hline
\end{tabular}

Table 28- Project 9 Workforce Requirements

Table 29- Project 9 Machinery Requirements

\begin{tabular}{|c|c|c|c|c|c|}
\hline \multirow{2}{*}{$\begin{array}{l}\text { Starting } \\
\text { Perrod }\end{array}$} & \multicolumn{5}{|c|}{ 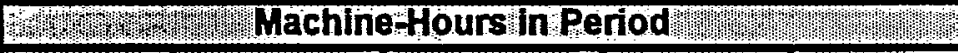 } \\
\hline & 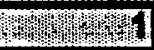 & 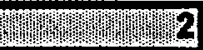 & 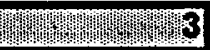 & MNAm man & Wminmme \\
\hline Wrmm & 35000 & 40000 & 35000 & 0 & 0 \\
\hline 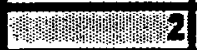 & 0 & 37000 & 42000 & 37000 & 0 \\
\hline 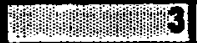 & 0 & 0 & 39000 & 45000 & 39000 \\
\hline 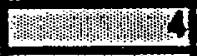 & 0 & 0 & 0 & 0 & 0 \\
\hline 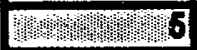 & 0 & 0 & 0 & 0 & 0 \\
\hline
\end{tabular}


Table 30- Project 10 Financial Requirements

\begin{tabular}{|c|c|c|c|c|c|}
\hline \multirow{2}{*}{$\begin{array}{l}\text { Starting } \\
\text { Penod }\end{array}$} & \multicolumn{5}{|c|}{ Den } \\
\hline & 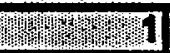 & 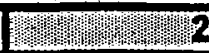 & 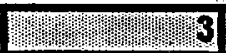 & Dimina & DIm:125 \\
\hline 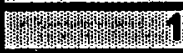 & 100 & $\overline{0}$ & 0 & $\mathbf{0}$ & 0 \\
\hline 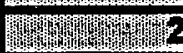 & 0 & 105 & 0 & $\overline{0}$ & $\overline{0}$ \\
\hline 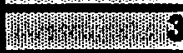 & 0 & $\overline{0}$ & 110 & $\overline{0}$ & 0 \\
\hline 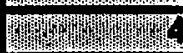 & 0 & $\overline{0}$ & 0 & $\overline{115}$ & $\overline{0}$ \\
\hline 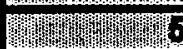 & 0 & $\overline{0}$ & $\overline{0}$ & 0 & 120 \\
\hline
\end{tabular}

Table 31- Project 10 Workforce Requirements

\begin{tabular}{|c|c|c|c|c|c|}
\hline \multirow{2}{*}{$\begin{array}{l}\text { SFrntpom } \\
\text { Portod }\end{array}$} & \multicolumn{5}{|c|}{ 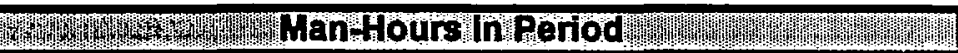 } \\
\hline & 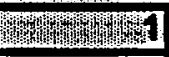 & 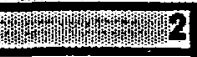 & 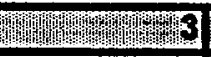 & 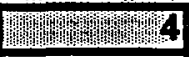 & 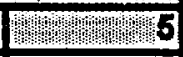 \\
\hline 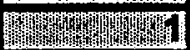 & 1200 & 0 & 0 & 0 & 0 \\
\hline 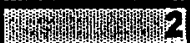 & 0 & 1210 & 0 & 0 & 0 \\
\hline 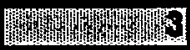 & 0 & 0 & 1220 & 0 & 0 \\
\hline 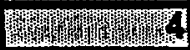 & $\mathbf{0}$ & 0 & 0 & 1230 & 0 \\
\hline 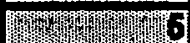 & $\overline{0}$ & 0 & 0 & 0 & 1240 \\
\hline
\end{tabular}

Table 32- Project 10 Machinery Requirements

\begin{tabular}{|c|c|c|c|c|c|}
\hline \multirow{2}{*}{$\begin{array}{l}\text { Sartingm } \\
\text { Pernod }\end{array}$} & \multicolumn{5}{|c|}{ 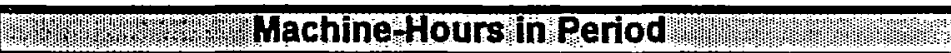 } \\
\hline & 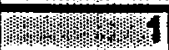 & 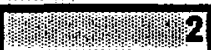 & 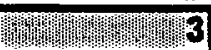 & mimmintin & 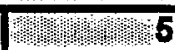 \\
\hline 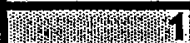 & 10000 & 0 & 0 & 0 & $\overline{0}$ \\
\hline 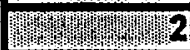 & 0 & 10200 & 0 & 0 & $\overline{0}$ \\
\hline 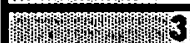 & $\overline{0}$ & 0 & 10400 & 0 & $\overline{0}$ \\
\hline 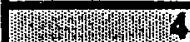 & $\overline{0}$ & $\overline{0}$ & $\overline{0}$ & 10500 & $\overline{0}$ \\
\hline 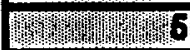 & $\overline{0}$ & 0 & $\mathbf{0}$ & 0 & 10600 \\
\hline
\end{tabular}


Table 33- Project 11 Financial Requirements

\begin{tabular}{|c|c|c|c|c|c|}
\hline \multirow{2}{*}{$\begin{array}{l}\text { Staring } \\
\text { Period }\end{array}$} & \multicolumn{5}{|c|}{ 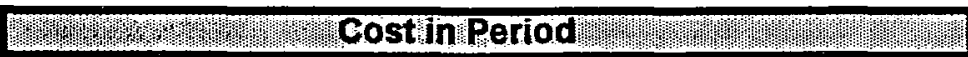 } \\
\hline & - & 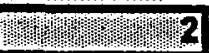 & Mmanming & DIVImIn 4 & 4. \\
\hline 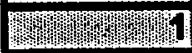 & 200 & 200 & 0 & & 0 \\
\hline 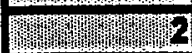 & 0 & 210 & 210 & & $\overline{0}$ \\
\hline 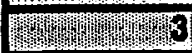 & $\overline{0}$ & 0 & 220 & 220 & $\overline{0}$ \\
\hline WNm & $\overline{0}$ & $\overline{0}$ & 0 & 230 & 230 \\
\hline mIrmW & $\overline{0}$ & $\mathbf{0}$ & $\overline{0}$ & 0 & 0 \\
\hline
\end{tabular}

Table34- Project 11 Workforce Requirements

\begin{tabular}{|c|c|c|c|c|c|}
\hline \multirow{2}{*}{$\begin{array}{l}\text { Startipopm } \\
\text { Period }\end{array}$} & \multicolumn{5}{|c|}{ 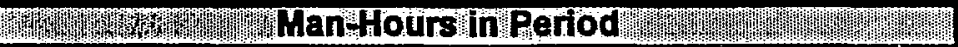 } \\
\hline & 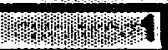 & 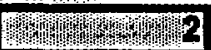 & 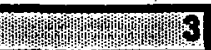 & 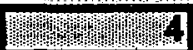 & MmMm: \\
\hline WMI & 2200 & 2200 & 0 & $\mathbf{0}$ & 0 \\
\hline 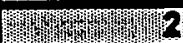 & $\mathbf{0}$ & 2210 & 2210 & $\mathbf{0}$ & $\mathbf{0}$ \\
\hline 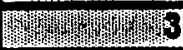 & 0 & 0 & 2220 & 2220 & 0 \\
\hline 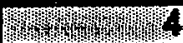 & 0 & 0 & 0 & 2230 & 2230 \\
\hline 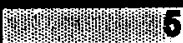 & $\overline{0}$ & $\overline{0}$ & $\overline{0}$ & 0 & $\overline{0}$ \\
\hline
\end{tabular}

Table 35- Project 11 Machinery Requirements

\begin{tabular}{|c|c|c|c|c|c|}
\hline \multirow{2}{*}{ Starting } & \multicolumn{5}{|c|}{ 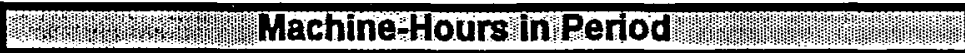 } \\
\hline & mImIm: & 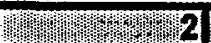 & 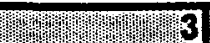 & 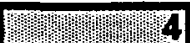 & Wh \\
\hline Mmmmint & 25000 & 25000 & 0 & 0 & 0 \\
\hline 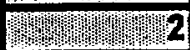 & 0 & 26000 & 26000 & 0 & $\mathbf{0}$ \\
\hline mWmmpm & 0 & 0 & 27000 & 27000 & 0 \\
\hline 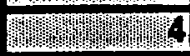 & 0 & 0 & 0 & 28000 & 28000 \\
\hline 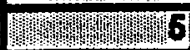 & $\overline{0}$ & 0 & 0 & 0 & 0 \\
\hline
\end{tabular}


Table 36- Project 12 Financial Requirements

\begin{tabular}{|c|c|c|c|c|c|}
\hline \multirow{2}{*}{$\begin{array}{l}\text { Starting } \\
\text { perisod }\end{array}$} & \multicolumn{5}{|c|}{ 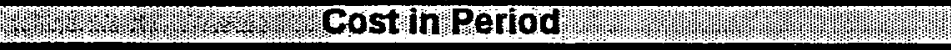 } \\
\hline & WMInI & 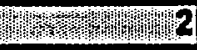 & 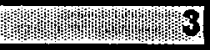 & 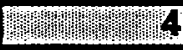 & MImIn!mo \\
\hline 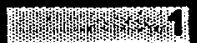 & 300 & 500 & 300 & 0 & 0 \\
\hline 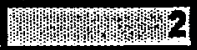 & 0 & 310 & 520 & 310 & 0 \\
\hline mWmentmas & 0 & 0 & 320 & 540 & 320 \\
\hline mpyns & 0 & 0 & 0 & 0 & 0 \\
\hline 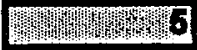 & 0 & 0 & 0 & 0 & 0 \\
\hline
\end{tabular}

Table 37- Project 12 Workforce Requirements

\begin{tabular}{|c|c|c|c|c|c|}
\hline \multirow{2}{*}{$\begin{array}{l}\text { Starding } \\
\text { Pentody }\end{array}$} & \multicolumn{5}{|c|}{ 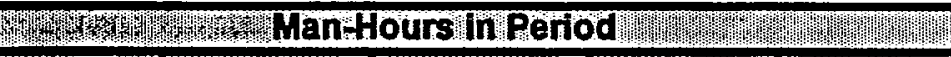 } \\
\hline & W & 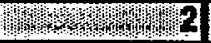 & 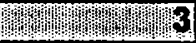 & WMWWW & 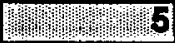 \\
\hline mint & 3500 & 5000 & 3500 & 0 & $\overline{0}$ \\
\hline 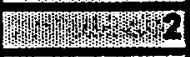 & 0 & 3600 & 5100 & 3600 & 0 \\
\hline 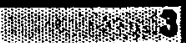 & 0 & 0 & 3700 & 5200 & 3700 \\
\hline 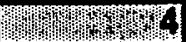 & 0 & 0 & 0 & 0 & 0 \\
\hline 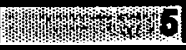 & 0 & 0) & 0 & 0 & 0 \\
\hline
\end{tabular}

Table 38- Project 12 Machinery Requirements

\begin{tabular}{|c|c|c|c|c|c|}
\hline \multirow{2}{*}{$\begin{array}{l}\text { Starting } \\
\text { Perrod }\end{array}$} & \multicolumn{5}{|c|}{ 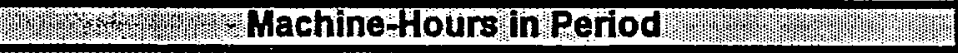 } \\
\hline & WWW:WII & 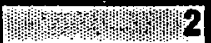 & 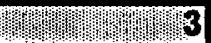 & 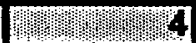 & 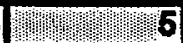 \\
\hline 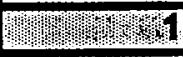 & 35000 & 40000 & 35000 & 0 & 0 \\
\hline WWWWT2 & 0 & 37000 & 42000 & 37000 & 0 \\
\hline 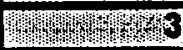 & 0 & 0 & 39000 & 45000 & 39000 \\
\hline 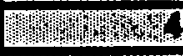 & 0 & 0 & 0 & 0 & 0 \\
\hline mWmmmons & 0 & 0 & 0 & 0 & 0 \\
\hline
\end{tabular}


Table 39- Optimal Solution

\begin{tabular}{|c|c|}
\hline Variable & Value: \\
\hline X(P1T) & 1 \\
\hline 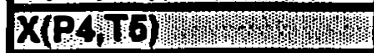 & 9 \\
\hline X(P7/T) & 9 \\
\hline 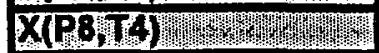 & $\overline{1}$ \\
\hline$X(P 10$ MI)WWWW & 1 \\
\hline 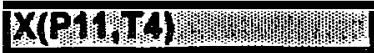 & 1 \\
\hline X(R12,T2) & 1 \\
\hline WWWW & \\
\hline 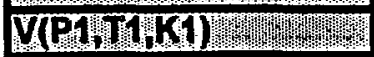 & 1 \\
\hline 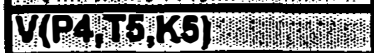 & 1 \\
\hline 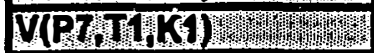 & $\overline{1}$ \\
\hline 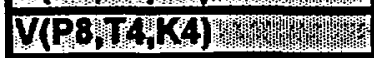 & 1 \\
\hline V(P8TL/K4) & 9 \\
\hline V(P10:11K1) & $\overline{1}$ \\
\hline 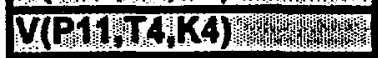 & 1 \\
\hline V(P114T5:K4) & 1 \\
\hline V(P12,T2;K2) & 1 \\
\hline $\mathrm{V}(\mathrm{P} 12 \mathrm{i}, \mathrm{K}, \mathrm{K}) \mathrm{m}$ & 1 \\
\hline $\mathrm{V}(\mathrm{P} 12 ; \mathrm{TA}, \mathrm{K} 2)$ WWW & 1 \\
\hline
\end{tabular}

